\title{
Família e proteção social: uma relação continuamente (re)atualizada
}

\section{Family and social protection: a relationship with continuous updates}

\section{Solange Maria Teixeira*}

Resumo: O objetivo deste artigo é retratar e analisar a relação família/sistemas de proteção social, demonstrando que a família sempre foi um dos elementos constitutivos desses sistemas, juntamente com o mercado e o Estado, mesmo em fase de maior intervenção do Estado nas refrações da questão social - todavia mais presente e constantemente acionada nos modelos mais conservadores. Destacam-se e discutem-se ainda suas reatualizações em função das reformas neoliberais e da legitimação dos novos mix público/privado na provisão social.

Palavras-chave: Família. Sistema de Proteção Social. Neoliberalismo.

\begin{abstract}
This paper aim is to portray and analyze the relationship between families/social protection systems, demonstrating that family has always been one of the constituent elements of these systems, along with the market and the state, even at stages of greater state intervention in the refractions of the social question. However, they are more present and consistently activated in the more conservative models. The new updates are highlighted and discussed in function of the neoliberal reforms and the legitimacy of the new public/private mix in social provision.
\end{abstract}

Keywords: Family. Social Protection System. Neoliberalism.

Recebido em: 20/04/2012. Aceito em: 14/11/2012.

\footnotetext{
* Pós-doutora em Serviço Social pela Pontifícia Universidade Católica de São Paulo (PUC-SP). Doutora em Políticas Públicas pela Universidade Federal do Maranhão (UFMA). Mestre em Serviço Social pela PUC-SP. Professora da Pós-Graduação em Política Públicas e do Departamento de Serviço Social da Universidade Federal do Piauí (UFPI). Teresina, Piauí, Brasil. E-mail: solangemteixeira@hotmail.com
} 


\section{Introdução}

No contexto da análise das transformações dos sistemas de proteção social, sob os efeitos das restrições econômico-financeiras pós anos 1970, a sociedade civil, e, mais especificamente, a família, aparecem com renovado papel na proteção social. Sobre ela têm recaído expectativas diversas, inclusive a expectativa de que continue a ser elemento de integração social, de proteção aos seus membros, de socialização, educação e lugar dos cuidados.

Vale ressaltar que os estudos comparativos dos modelos de Welfare State, especialmente as particularidades da Europa do Sul, desenvolvidos por Ferrera (2000; 2005), mostram como a família historicamente se constituiu nesses países como fonte de bem-estar social para seus membros mediante um conjunto de serviços de cuidados infantis, assistência aos desempregados e enfermos e cuidados com pessoas idosas e deficientes, diante de um Estado subdesenvolvido em serviços de apoio à família.

Os estudos de Saraceno (1992) demonstram que, em muitos países europeus, a família é uma "parceira explícita" do Estado de Bem-Estar Social. Nesse contexto, as críticas feministas exigiram que se recuperasse o desvio gerado pelas análises anteriores dos regimes de bem- estar social centrados na dicotomia entre Estado e Mercado, incluindo a família como provedora de serviços - graças ao trabalho não pago das mulheres, pouco contabilizado e levado em consideração pela economia política. Isso também levou à reconsideração dos estudos generalistas da teoria da modernização sobre a perda de funções da família, e em especial a perda de função de proteção social das instituições especializadas e do Estado, obrigando-os a relativizar as determinações desse processo em muitos países, principalmente os de modernização tardia.

Estudos em outros continentes, como os de Franzoni (2008), na América Latina, igualmente destacam o "familismo" característico da maioria dos países desse continente, em que a família, com suas estratégias de sobrevivência, apoios e cuidados, constitui fonte ativa de proteção social diante de um sistema pouco desenvolvido, ou em situações de retração do Estado, advinda das reformas neoliberais nas últimas décadas, e de um mercado de trabalho pouco inclusivo.
O "ressurgimento" da família - ou as expectativas em relação às suas funções de proteção social, inclusão e integração social - é favorecido nas últimas décadas. Esse favorecimento se diante do recuo do Estado no provimento social, da defesa de um regime de bem-estar plural que envolve o mix público/privado na provisão social, e de propostas neoliberais para que a intervenção estatal ocorra apenas quando cessem as fontes naturais de proteção social - sejam as formais, como mercado e terceiro setor, sejam as informais, como família e comunidade.

Assim, embora seja estratégico e econômico contar com a família para potencializar a proteção social oferecida, considerando sua tradicional e cultural função na reprodução social, há sinais de que a proteção familiar não pode ser estendida e sobrecarregada para além de sua capacidade. Em relação a isso, alguns aspectos devem ser considerados: a ausência de cuidadores em tempo integral, com a inserção das mulheres no mercado de trabalho a partir da necessidade de compartilhar a função provedora com o cônjuge ou até mesmo de desempenhá-la sozinha, ou pelo interesse em participar do mercado de trabalho como elemento de mobilização social e status; as transformações urbanas e a redução das redes de apoio; a redução do tamanho das famílias; a fragilidade de renda e de proteção pública e a vulnerabilidade que reduzem a capacidade cuidativa da família e a disponibilidade das mulheres para o cumprimento desse papel.

O objetivo deste artigo é retratar e analisar a relação entre família e sistemas de proteção social, em que a família aparece como um dos elementos constitutivos desses sistemas, juntamente com o mercado e o Estado, mesmo em fase de maior intervenção estatal nas refrações da questão social. Também se analisam suas reatualizações em função das reformas neoliberais e da legitimação dos novos mix público/privado na provisão social.

\section{O lugar da família nos sistemas de proteção social}

Não existe sociedade humana que não tenha desenvolvido algum sistema de proteção social. A isso, Di Giovanni (1998, p. 10) denomina como "as formas - às vezes mais, às vezes menos, institucionalizadas - que as sociedades 
constituem para proteger parte ou o conjunto de seus membros", com diferentes formas de alocação de recursos e esforços para desenvolver essas atividades.

A formação dos sistemas de proteção social tem origem nas necessidades das sociedades de impedir ou diminuir o impacto de determinados riscos sobre os indivíduos ou grupos sociais. Tais riscos decorrem de certas vicissitudes da vida natural ou social, como a velhice, a infância, a doença, a invalidez, as privações, o desemprego, dentre outros (DI GIOVANNI, 1998; VIANA; LEVCOVITZ, 2005).

Castel (1998), utilizando a noção de solidariedade de Alan Caillé, conceitua os sistemas de proteção social a partir da distinção entre sociabilidade primária, em que as ações de proteção são realizadas pela família, pela vizinhança, pelos grupos de trabalho (e até as formas mais organizadas de filantropia, que buscavam restituir esse princípio natural da solidariedade local, da proteção face a face aos que pertencem à comunidade), e sociabilidade secundária ou solidariedade institucionalizada, em que as ações de proteção social são realizadas pelo Estado por meio das políticas públicas.

Nessa perspectiva, "o exercício vital das famílias é semelhante às funções das políticas públicas: ambas visam dar conta da reprodução e da proteção social dos grupos que estão sob sua tutela" (CARVALHO, 2005, p. 267). A diferença é que uma se efetiva no âmbito privado e a outra na esfera pública, no campo dos direitos à proteção social. Mas, como destaca essa autora, se, nas sociedades tradicionais e pré-capitalistas, a família se ocupava quase exclusivamente dessas funções, nas sociedades contemporâneas tais funções são compartilhadas com o Estado.

Isso ocorre porque a magnitude dos problemas sociais, sua dimensão estrutural e as lutas travadas para que tais problemas sejam reconhecidos como de responsabilidade pública, bem como a capacidade de mobilização (tanto da classe social submetida aos maiores riscos quanto da classe dominante, em sua resposta às crises e problemas sociais), fundaram uma nova legitimidade no formato da proteção social, desde o final do século XIX. Segundo Di Giovanni (1998, p. 15), "trata-se da presença do Estado como organizador, produtor, gestor e normatizador dos sistemas de proteção social".
Conforme o autor, em cada país esse sistema público ganha matizes específicas, adaptadas a condições políticas, econômicas e culturais particulares, "mas o fato inexorável é que o Estado [...] passou a assumir, com maior ênfase, as funções mencionadas" (Idem).

A teoria da modernização e suas variantes de viés estrutural-funcionalista têm sustentado a tese da redução das funções da família, da perda de sentido e de autônoma capacidade de ação, com a industrialização, a urbanização e o Estado intervencionista. Segundo essa teoria, principalmente a partir do século $X X$, a família $e$ os demais provedores informais de bem-estar, como a vizinhança e a comunidade, foram perdendo funções, as quais haviam sido transferidas total ou parcialmente a instituições públicas especializadas. Essa visão se tornou consenso entre vários estudos.

Para as análises marxistas, a raiz subjacente a essas mudanças são as relações de produção capitalista, com as novas formas de organização do trabalho mediante o trabalho assalariado e o valor econômico dos indivíduos como força de trabalho. A empresa capitalista orientada para o lucro transforma a família. Primeiramente, retira suas funções de produção, com a expropriação dos meios de produção e com a submissão da economia doméstica à economia de mercado. Em seguida, transfere boa parte das funções de socialização e educação e suas responsabilidades na proteção de seus membros para instituições especializadas.

As esferas da produção e da reprodução são espacialmente dissociadas e dicotomicamente opostas na relação entre público e privado, que, conforme Lavinas (1994, p. 172-3), foram as bases nas quais por tanto tempo se assentou a doutrina liberal. "Assim surge, por um lado, a família como paradigma do privado, espaço da vida doméstica, das relações interpessoais, lugar do feminino, da subjetividade", esfera da intimidade, ${ }^{1}$ lugar de refúgio, espaço de consumo, da reprodução física e social dos indivíduos e da integração emocional. "Por

\footnotetext{
${ }^{1}$ Horkheimer e Adorno (1987) destacam que precisamente a esfera da intimidade, que pareceria decisiva para definir a família na sociedade moderna, é de natureza social, ou seja, determinada socialmente pelas relações de produção burguesas, e, portanto, não pode ser separada do princípio do trabalho assalariado.
} 
outro lado, o domínio público, dos interesses interpessoais, portanto, civis e universais, lugar do político por excelência e dos negócios, arena exclusiva dos homens" (Idem).

Outros estudos, seguindo uma linha teórica divergente da teoria da modernização, chegaram a conclusões semelhantes. Destacam que, com o avanço da urbanização, da industrialização e da modernização da sociedade, ainda que persistam a pequena agricultura camponesa, as indústrias caseiras e as empresas domésticas urbanas, atividades econômicas ancoradas em relações familiares perderam relevância, e, em geral, já não se pode caracterizar a família como unidade de produção.

Habermas (1984) diz que a redução da propriedade familiar aos rendimentos de cada um de seus membros - com o trabalho assalariado - rouba à família a possibilidade de cuidar de si mesma. Entretanto, ele aponta um novo fenômeno, a inter-relação entre as esferas pública e privada, com o processo que denomina "desprivatização da família" ou "estatização da família", quando o Estado, com as demandas do trabalho e do capital, passa a intervir e assume para si muitas das funções da esfera familiar, como a reprodução social, momento em que a família é "desprivatizada através das garantias públicas de seu status" (HABERMAS, 1984, p. 184).

Heller (1987), em seus estudos sobre a família e o Estado de Bem-Estar Social, também destaca que, com a separação entre Estado e sociedade civil, as relações de mercado e a industrialização modificaram o status social da família. Aponta que a família moderna perdeu importantes funções em relação aos modelos precedentes e que em todos os Estados de Bem-Estar a família encontra-se em vias de dissolução, principalmente nos modelos mais universalistas, à medida que o Estado assume os serviços familiares - essa posição do Estado torna a família supérflua, principalmente sob o perfil da produção e do consumo, embora ela mantenha, apesar de minimizadas, as funções de reprodução e educação dos filhos. Heller (1987, p. 20) ressalta:

O Estado se faz "materno", garantindo ao indivíduo sua sobrevivência material, educação e saúde; é o Estado a ocupar-se de tudo isso assumindo praticamente responsabilidade exclusiva. Desfaz-se a última comunidade da história, pois a sociedade substitui radicalmente todo tipo de comunidade.

Os estudos e investigações recentes sobre família questionam se essa e outras descrições que vão nessa direção, como as da teoria da modernização, são adequadas ou verdadeiras. Para muitos autores (ESPING-ANDERSEN, 1999; SUNKEL, 2006), elas devem ser relativizadas. Como destaca Esping-Andersen (1999), a família padrão pode não ser mais a principal unidade produtora para o mercado, mas certamente fornece mercadorias não monetarizadas e serviços.

Sunkel (2006) destaca que descrições como as da teoria da modernização são historicamente inadequadas, especialmente na América Latina, quando se relacionam as funções protetivas e de bem-estar da família a seus membros.

Portanto, esses estudos tendem a relativizar essa "desfuncionalização" anunciada, a "dissolução" ou perda de status da família nas sociedades capitalistas, principalmente em seu papel econômico e de bem-estar. É inegável que pelo menos as famílias urbanas, com o desenvolvimento das forças produtivas, realmente deixaram de se caracterizar como "unidade de produção". Mas, como destaca Silva (1987, p. 49), isso, entretanto, não significa que tenham deixado de desempenhar um papel econômico, uma vez que "o papel de reprodutora de seres humanos e também as tarefas que desempenha em sua socialização e reposição da força de trabalho, assim como o consumo que realiza enquanto grupo, dão a essa instituição um caráter econômico por excelência".

Silva (1987) destaca o papel da família na reprodução social da força de trabalho, não apenas biológica, mais social e ideologicamente ${ }^{2}$ - funções articuladas e indispensáveis à ordem capitalista, que são supridas por uma grande parcela de trabalho realizado no lar, em especial pelas mulheres, que tem como consequência, no

\footnotetext{
${ }^{2}$ A reprodução biológica está relacionada à procriação e à manutenção da espécie; a social e ideológica à reprodução de valores sociais, convenções, relações padrões (hierarquizadas) entre gênero e gerações - embora a família seja espaço de movimento, de manutenções e também de mudanças, estando em estreita relação com o Estado e a sociedade.
} 
caso das mulheres que trabalham fora do lar, o advento da dupla jornada de trabalho. Aponta também a família como sendo uma unidade de consumo, para a qual se dirige o próprio apelo ao consumo.

No entanto, em contexto de separação da produção social da produção privada, essa reprodução social realizada no âmbito doméstico, a cargo das mulheres e da família, é analisada pelos economistas clássicos como destituída de valor, já que não pode ser medida pelo tempo socialmente necessário para sua reprodução. Vale ressaltar que no interior das famílias se recriam as condições de divisão social e sexual do trabalho, quando se separam as forças masculinas e femininas, dando-lhes atribuições e setores distintos de trabalho: ao homem, a produção social, à mulher, a produção privada, reproduzida e recriada nos modelos ideais de família difundidos pelo Estado e pela ordem social.

As investigações feministas têm criticado severamente os estudos da teoria da modernização e da economia política dos Estados de Bem-Estar - centrados, em sua caracterização dos regimes de bem-estar social, no modelo homem provedor/mulher cuidadora e na relação mercado/ Estado. Tais investigações têm mostrado que o modelo clássico de família do período pós-guerra nunca deixou de ser uma unidade produtora e provedora de serviços, devido em grande parte ao trabalho da mulher no âmbito doméstico.

Esping-Andersen (1999) reconhece que o paradigma da economia política que sustentou a pesquisa sobre o Estado de Bem-Estar Social nos anos 1980 pouco fez para ressuscitar o interesse pela família como elemento constitutivo dos regimes de bem-estar. O autor salienta que a lente analítica dessas pesquisas estava fixada na batalha entre Estado e mercado. Os próprios estudos de Esping-Andersen se incluem nessas tendências, embora já incluíssem em sua tipologia a relação Estado/mercado/família. Todavia, é o grau de desmercadorização - isto é, o quanto os sistemas subtraem o trabalhador/cidadão da dependência do mercado, e com ele sua família - a categoria de análise determinante.

Portanto, a família tem um tratamento residual na caracterização dos modelos de bem-estar analisados pela economia política na década de 1980. Aderindo à crítica feminista, Esping-Andersen (1999) reconhece que, mesmo que em geral o longo movimento histórico tenha reduzido o papel da unidade familiar na produção de bem-estar social, esse fato não é linear, e nem é regra geral, havendo uma variação muito grande entre os países. Alguns países são caracterizados por seu avançado nível de "desfamiliarização" das responsabilidades do bem-estar - como os países do Norte da Europa. Outros reproduzem muitos aspectos da unidade familiar "pré-industrial", em que a família é responsável por grande parte dos cuidados dispensados a seus membros. Segundo Campos (2008a), é o caso, por exemplo, da Europa do Sul. Para a autora, na França e na Alemanha, a família continua responsável por esses cuidados, mas é bastante subsidiada em sua atuação.

Na década de 1990, os estudos de Esping-Andersen (1999, p. 49) contradizem alguns consensos sobre a teoria da modernização, concluindo que "simplesmente é errado considerar que ela (a família) perdeu suas funções de bem-estar social com o advento dos Estados de Bem-Estar Social".

Campos (2008a) destaca que o projeto de Estado, cuja proteção social é constituinte de suas obrigações, desenvolveu-se com grande diversidade e variação, tanto entre os países europeus quanto nos demais continentes, em que a família permaneceu bastante atuante quanto à proteção social de seus membros. Em alguns casos, houve inclusive ampliação das funções da família, como a participação também nos benefícios, subsídios e serviços ${ }^{3}$ estatais. Essas diferenças são engendradas pelas especificidades de processos sociais, históricos, culturais e políticos de cada país, que repercutem na configuração do Estado intervencionista.

Em estudo conjunto, Campos, Mioto e Lima (2006) concluem que a família não foi privada de

\footnotetext{
${ }^{3}$ É o que Saraceno (1992), analisando o caso italiano, denomina de "sistema família-serviço", para definir a presença da família como parceira do Estado e a sobrecarga de responsabilidade mesmo quando o Estado intervém com serviços. Isso porque o "uso de qualquer serviço exige como pressuposto indispensável uma parte de prestação familiar, como o cumprimento das práticas burocrático-administrativas necessárias para fruir delas e às vezes para estabelecer o direito de cada um à própria fruição [...], às formas de participações formais e informais exigidas, à integração das eventuais deficiências dos serviços". A autora também destaca: "o uso de serviços exige que a família organize o seu tempo e os recursos internos em torno dos tempos e das exigências dos próprios serviços" (p. 216).
} 
suas funções, nem está em vias de dissolução após a estruturação do Estado de Bem-Estar Social, quando ganha legitimidade o enfrentamento coletivo dos riscos sociais mediante a intervenção do Estado sobre a questão social. Assim, afirmam: "a família continuou funcionando também como unidade econômica e de serviços, tornando-se através da divisão do trabalho e responsabilidades (entre gênero e gerações) e com sua estrutura assimétrica de interdependência, em parceira explícita do Estado de Bem-Estar Social" (MIOTO et al., 2006, p. 108).

Em estudos recentes, Esping-Andersen introduz a categoria "desfamiliarização" ao lado da categoria "desmercadorização", ou seu contrário, a categoria "familismo", para examinar o grau em que as famílias absorvem os riscos sociais nos regimes de Estado de Bem-Estar Social.

Deve-se ressaltar que, para esse autor (1999, p. 51), "desfamiliarização" não implica "antifamília". Ao contrário, o termo se refere ao grau no qual as responsabilidades de bem-estar social e cuidados das unidades familiares são reduzidos pela provisão de serviços públicos ou ofertados pelo mercado. Significa também o grau em que a política social torna as mulheres autônomas, reduzindo sua carga horária de serviços domésticos ou ampliando suas chances de se inserir no mercado de trabalho. Assim, o "familismo" não pode ser confundido com "pró-família", mas o autor aponta que nessa tendência há uma maior responsabilização da família pelo bem-estar de seus membros (bem-estar também incentivado pelas políticas públicas).

\section{A família e os regimes comparativos de bem-estar social}

Em relação aos regimes de bem-estar na Europa, Esping-Andersen (1999) faz um novo balanço nos anos 1990, pós-reformas dos sistemas e verificação da contribuição relativa da família para o complexo do bem-estar social, verificando como essa participação afeta o seu entendimento dos regimes de bem-estar social. O autor busca verificar essa questão a partir da análise do grau de desfamiliarização, ou seja, observando em que medida os regimes de bem-estar social absorvem os encargos familiares. Para isso, utilizou vários indicadores, tais como: a) compromisso de atendimento geral, por meio das despesas com serviços não relacionados com a saúde da família com percentagem do PIB; b) compromisso geral de subsidiar famílias com crianças (valor combinado do auxílio família e deduções de imposto); c) difusão de creches públicas; d) fornecimento de cuidados a idosos em domicílio (percentagem de idosos com 65 anos ou mais recebendo serviços de ajuda em domicílio).

Esping-Andersen destaca ainda outros indicadores, como a intensidade das responsabilidades familiares de bem-estar social medidas pelo tempo gasto nas obrigações domésticas, ou pelo grau no qual a família absorve os encargos sociais - por exemplo, mantendo no domicílio idosos ou filhos adultos, que, devido ao desemprego, são incapazes de formar novas unidades familiares. Além disso, verifica a desfamiliarização que ocorre por meio dos mercados, mediante a oferta de serviços e o custo líquido expresso em percentagem da renda familiar.

As conclusões de Esping-Andersen (1999) reforçam os três modelos de regime de bem-estar já indicados em estudos anteriores, descartando a possibilidade de um quarto regime para países da Europa do Sul e Japão. São eles: o regime social-democrata, o regime conservador e o regime liberal.

\section{a) O regime social-democrata}

O regime social-democrata agrupa os países escandinavos (Noruega, Dinamarca, Suécia e Finlândia) que têm no Estado seu lócus principal de provisão de serviços e bem-estar social. Orienta-se pela cobertura universal dos cidadãos e apresenta uma provisão de serviços sociais e níveis generosos de benefícios públicos. Em termos de princípios, esse regime tende ao igualitarismo, buscando reduzir ao mínimo a distribuição desigual de recursos segundo a origem familiar - portanto, baseia-se nos princípios da universalidade, da solidariedade e da igualdade, pondo em prática um leque amplo de medidas de proteção social para todos e com caráter redistributivo. Os serviços e benefícios são assegurados com base no critério de cidadania e não nos critérios de necessidades, desempenho ou status dos indivíduos no mercado, e são ofertados independentemente de contribuição prévia.

Assim, o regime social-democrata apresenta um maior grau de "desmercadorização" 
dos direitos sociais, possibilitando maior autonomia de indivíduos e famílias em relação ao mercado.

Examinando a participação da família nos regimes de bem-estar social, o autor encontrou uma imagem que denomina "bimodal". Em um dos extremos, está o bem-estar social dos países nórdicos, com maior grau de "desfamiliarização", entendido como coletivização das necessidades das famílias. Ou seja, há maior responsabilidade do conjunto da sociedade sobre o bem-estar e a satisfação das necessidades dos membros da família, e tal responsabilidade é expressa em maior percentagem de gasto social em serviços domiciliar, cobertura de creches e de ajuda aos idosos, e ainda estão presentes políticas e serviços que socializam os custos da família e minimizam a dependência do indivíduo, em particular da mulher, em relação à família e ao mercado.

É nesse sentido que Sunkel (2006, p. 21) afirma que a "desfamiliarização" faz referência a um Estado de Bem-Estar "amistoso" com a mulher, à medida que incentiva sua independência econômica. Assim, libera-a das obrigações familiares que restringem sua participação no mercado de trabalho, cobrindo serviços que antes eram de sua responsabilidade e realizados no domicílio e facilitando sua integração no mercado de trabalho.

Navarro (2002) ressalta que não é por acaso que, entre os países da União Europeia, os que têm maior participação da mulher no mundo do trabalho (74\%) sejam os nórdicos, onde existe maior desenvolvimento de serviços de apoio à família e inserção das mulheres como força de trabalho nos serviços públicos.

No outro extremo encontram-se os sistemas liberais, os sistemas mediterrâneos e o Japão. Em relação à "desfamiliarização", medida em termos de previsão pública de serviços para a família, verifica-se uma baixa oferta de serviços públicos dirigidos à família, e sobre esta recaem maior carga e responsabilidade. (ESPING-ANDERSEN, 1999, p. 61).

Em relação a todas as variáveis analisadas, o sul da Europa e o Japão mostram provisões extremamente baixas, mas, segundo o autor, isso não merece um rótulo separado para os regimes desses países, principalmente porque os benefícios familiares diretos são verdadeiramente pequenos em todos os países da
Europa continental - também nesses países há maior penalização das famílias com dois provedores, mais que nos países da Europa do Sul, o que reafirma o caráter conservador e familista da Europa continental.

\section{b) $O$ regime conservador}

O regime conservador agrupa os países da Europa continental (Alemanha, Holanda, Áustria, França, Itália e Espanha). Nesse regime, os benefícios dependem da inserção no trabaIho formal, da renda e da contribuição prévia compulsória, elementos administrados e geridos pelo Estado. Segundo Esping-Andersen (1991, p. 109), o mercado e sua provisão de serviços nunca foram marcantes. O que predominava era a preservação das diferenças de status. Os direitos, portanto, estavam ligados à classe e ao status.

Assim, esse regime, também denominado corporativo ou meritocrático, se estruturou a partir do seguro social vinculado ao emprego, eminentemente masculino, reproduzindo a visão da família em moldes tradicionais, em que a família depende do homem como seu provedor principal, e a mulher, como esposa, acessa os benefícios da seguridade social na condição de dependente.

Historicamente, esse tipo de regime foi influenciado pelo estatismo monarquista, o corporativismo tradicional e a doutrina social católica, que lhe deram suas características básicas de segmentação de status e "familismo". O "familismo" se expressa pelo baixo nível dos serviços dirigidos às famílias e cobertos pelo Estado. Portanto, há Estados de Bem-Estar Social passivos quanto a esses serviços, e com sobrecarga dos cuidados relegados à família. $\mathrm{O}$ catolicismo influenciou a doutrina da subsidiaridade $^{4}$ na intervenção estatal, e, nesse regime,

\footnotetext{
${ }^{4}$ Campos (2008a), fundamentada nos estudos de Esping-Andersen, expressa bem o significado da noção de subsidiaridade defendida pelo catolicismo ao dizer que para "a Doutrina Social da Igreja - DSI, a interferência pública deve limitar-se a situações onde as unidades de menor porte da sociedade falham", e entre estas, destaca-se a família. Essa influência cultural influenciou um tipo de intervenção do Estado que só ocorre quando a família não consegue arcar com os cuidados e assistência aos seus membros, favorecida pela família tradicional do sul da Europa com sua extensa rede de solidariedade e o seu intenso fluxo de transferências intergeracionais.
} 
essa só deve ocorrer quando a capacidade de ajuda da família se exaure. Segundo Esping-Andersen (1999), essa influência é maior nos países do sul da Europa. Na França, a política social tem se guiado pelo espírito republicano e anticlerical, e, no Japão, pela doutrina confucionista - equivalente funcional do familismo católico - e pelo corporativismo.

A estratificação social seria a noção central para distinguir os programas sociais segmentados e a existência de uma incipiente intervenção do Estado para os que não conseguem obter o bem-estar a partir da inserção no mercado de trabalho. Além disso, está presente um explícito "familismo", no sentido de que, assegurada a renda advinda do trabalho, supõe-se que a família pode cumprir com a maioria das funções relacionadas ao bem-estar de seus membros. Como destaca Sunkel (2006), o "familismo" combina o corte da proteção social para o homem provedor com a centralidade da família como protetora e responsável última por seus filhos - e estes, quando adultos, como responsáveis pelos pais.

Como assevera Esping-Andersen (1999), muitos países ainda têm obrigações familiares legalmente definidas de assistência aos filhos ou aos pais em necessidade. Tais obrigações são comuns nos países da Europa Continental e Japão.

Segundo as análises desse autor, o peso da responsabilidade da família com os cuidados de seus membros parece bastante similar nos agrupamentos liberais e da Europa continental. Portanto, reforça a tese de não separação dos países da Europa do sul pelo "familismo".

\section{c) $O$ regime liberal}

O regime liberal agrupa os países anglo-saxônicos (Estados Unidos da América, Reino Unido, Nova Zelândia e Austrália). Nesse regime, predomina o mercado como lócus da proteção social, o Estado com políticas residuais para os comprovadamente pobres e as reduzidas transferências universais ou os planos modestos de previdência social pública. Segundo Esping-Andersen (1991, p. 108), "o Estado, por sua vez, encoraja o mercado, tanto passivamente - ao garantir apenas o mínimo - quanto ativamente ao subsidiar esquemas privados de previdência social".
Portanto, nesse tipo de regime, além da residualidade das políticas públicas, há uma individualização dos riscos, que devem ser supridos por soluções de mercado. Aintervenção do Estado é justificada para suprir as falhas do mercado junto aos segmentos sociais que comprovem a necessidade ou a incapacidade de comprar serviços no mercado.

Trata-se de um regime "dual" de tratamento dos problemas sociais, uma vez que nesse regime "os Estados de Bem-Estar Social têm em comum a adoção de um componente de tributação negativa, que oferece um piso mínimo de renda aos pobres e aos estratos de baixa renda, junto com o incremento dos incentivos aos setores de maior renda para contratarem serviços pagos" (ESPING-ANDERSEN, 2001 apud SUNKEL, 2006, p. 22).

Os serviços para os pobres são não contributivos. Todavia, exige-se teste de meios para comprovação da necessidade, com caráter estigmatizante da pobreza. Por outro lado, a evolução histórica desse tipo de regime demonstra que a proteção social do setor privado tem se deslocado da cobertura coletiva dos riscos - como os planos coletivos de seguro social por empresa - para uma cobertura individualizada de planos de previdência e saúde e prestação de serviços no mercado.

A "desfamiliarização" nesses regimes liberais não ocorre via Estado, com a provisão de serviços e subsídios por parte deste, mas por meio da substituição, pelo mercado, dos serviços domésticos ou de apoio às famílias. Esses serviços, conforme os estudos de Esping-Andersen (1999, p. 64), são mais baratos nos Estados Unidos que na Europa, e consomem uma percentagem menor da renda familiar (6\%). Por exemplo, "na Europa o custo por ano é de $20 \%$ da média de uma família com ambos trabalhando na Itália; $14 \%$ na Holanda e na França; e 12\% na Alemanha, isso para destacar apenas os serviços de creches privadas". Se incluirmos serviços de faxineiras, ajudantes domésticos, babás, esses serviços consumiriam uma fatia muito grande dos orçamentos domésticos. Nos Estados Unidos, em função da desregulamentação dos mercados, esses serviços são mais baratos e as famílias podem usá-los. Todavia, as soluções de mercado geram desigualdades, porquanto as famílias de baixa renda não podem comprar esses serviços, pois são excluídas. 


\section{O Estado de Bem-Estar Social Mediterrâneo ou Latino: subtipo do regime conservador ou um novo regime?}

As investigações sobre os regimes de bem-estar social cresceram nos anos 1990, e muitos autores, mais sensíveis às peculiaridades históricas de países e regiões que não estão bem ajustados às classificações estabelecidas, buscaram construir novas categorias de regimes e de Estados de Bem-Estar Social.

Dentro dessa perspectiva, destacam-se os estudos de Ferrera (2000), que visam captar as peculiaridades dos países da Europa do Sul (Portugal, Espanha, Itália e Grécia) a partir dos conceitos de regime de bem-estar do Sul da Europa ou regime de bem-estar Mediterrâneo (FERRERA, 2000), ou regime de bem-estar Latino (ABRAHAMSON, 1992). Como destacam Rhodes e Flaquer (1997, apud DRAIBE; RIESCO, 2006, p.22), há um esforço para superar o entendimento desses "casos" como subtipos de outros regimes ou como modalidades não desenvolvidas, incipientes ou atrasadas, observando-os em suas configurações próprias.

Ferrera (2000) destaca as peculiaridades dos países da Europa do Sul, com sua modernização tardia e as características comuns a suas economias políticas contemporâneas, bem como suas características de sua política social - apesar das diferenças significativas que há entre esses países. Ressalta que as investigações comparativas sobre os regimes de bem-estar social da década de 1980 nem incluíam tradicionalmente os países da Europa do Sul, com exceção da Itália. Os estudos dos anos 1990 confirmam, todavia, a existência de determinadas similitudes regionais, tais como:

O relativo subdesenvolvimento do Estado Social e a discrepância entre as medidas prometidas (e por vezes até legisladas) e as realmente levadas à prática; a importância e elasticidade da família como uma espécie de carteira de compensação para o bem-estar dos seus membros. (FERRERA, 2000, p. 459-60).

Além das características semelhantes ao modelo conservador, destaca-se o acentuado "familismo", em que a família "tem funcionado como uma eficaz (embora informal) rede de segurança: um 'amortecedor's e promotora de bem-estar para seus membros, [...] através dos cuidados infantis, assistência ao desempregado, os cuidados aos idosos e deficientes ou habitação". (MORENO, 2004; NALNI, 2003 apud FERRERA, 2005, p. 8).

Assim, considerada em seu conjunto, essa organização do bem-estar pressupõe o "familismo", ou o papel decisivo da família na provisão social, em que a família busca o bem-estar de seus membros, mediante transferências materiais e imateriais distribuídas no seu interior, especialmente o cuidado e o trabalho doméstico realizado pelas mulheres.

Destaca-se ainda como característica a forte influência da Igreja Católica e a reduzida presença do Estado em serviços de apoio à família. Navarro (2002), ao descrever a situação espanhola, salienta que a ausência dessas estruturas públicas de apoio à família tem também um aspecto econômico, que explica a baixa participação da mulher na força de trabalho; somente 38\% das mulheres adultas na Espanha estão integradas ao mercado de trabalho, quando a média na União Europeia é de $53 \%$, e, a dos países nórdicos, $74 \%$. Isso porque a sobrecarga das famílias, em especial das mulheres, cria dificuldades para que sejam conciliadas as responsabilidades profissionais e as familiares. Essa sobrecarga pode ser medida pela quantidade de horas semanais que as mulheres dedicam ao lar, cuidando de crianças, idosos, pessoas incapacitadas, jovens desempregados e pessoas adultas - na Espanha chega a 44 horas, a mais alta da União Europeia.

Portanto, a pergunta que Navarro (2002) faz sobre quem cobre as insuficiências do Estado de Bem-Estar Social da Espanha (inclusive Catalunha) tem como resposta a família - em particular a mulher -, que tem maior responsabilidade no que diz respeito aos cuidados e afazeres domésticos, realidade que se estende a outros países da Europa do sul. Essa constatação confirma a

\footnotetext{
${ }^{5}$ Paugan (em palestra na aula inaugural do primeiro semestre de 2009, na PUC-SP) em seus estudos recentes sobre a pobreza, trata o caso do sul da Europa como "pobreza integrada", à medida que os efeitos da crise e do desemprego são amortecidos pela família e a pobreza é, portanto, menos estigmatizada. Mas, como destaca Ferrera (2005, p.8) citando Moreno (2002), "esta síndrome tem, sem dúvida, resultados positivos em termos de inclusão: os pobres continuam a ser mais firmemente integrados ao tecido social. Mas também têm gerado algumas patologias socioeconômicas: as baixas taxas de emprego feminino e o dramático declínio da fecundidade entre as mulheres".
} 
tese de que a família não foi disfuncionalizada ou reduzida em suas funções de proteção social pelo processo de modernização nesses países mediterrâneos.

Pode-se dizer que até a década de 1960 os Estados de Bem-Estar Social reproduziam o modelo padrão de homem provedor/mulher cuidadora, considerando a ênfase em benefícios monetários, os quais as mulheres e os filhos acessavam como dependentes, a reduzida oferta de serviços, além da reduzida inserção das mulheres no mercado de trabalho. Esse modelo padrão se funda em relações assimétricas e hierarquizadas de gênero, e as reproduz. ${ }^{6}$ Como exemplo, na Espanha (inclusive na Catalunha), segundo os estudos de Navarro (2002), o companheiro ou marido dedica apenas seis horas semanais com trabalhos domésticos, enquanto o homem sueco dedica 22 horas semanais.

Assim, nesses países que veem a família e a sociedade civil como responsáveis pela proteção social de seus membros, sobrecarregando a família e a mulher, são nítidos a visão conservadora e o princípio de subsidiaridade da intervenção do Estado, daí o seu débil desenvolvimento em serviços.

A tendência contemporânea é de aprofundamento dessas características familistas dos regimes de bem-estar nos países do sul da Europa, nos países do leste e do sul da Ásia (Japão e os países recentemente industrializados), expandindo-se para a Europa continental, diante das reformas promovidas nas políticas públicas pelos Estados, em contexto de globalização e crise do capitalismo.

\section{"Ressurgimento" da família na proteção social ou reforço de suas funções}

Nesse quadro de restrições econômico-financeiras e de ações que visam reduzir as demandas do Estado, desde a década de 1970,

\footnotetext{
${ }^{6}$ Como destaca Saraceno (1992, p.183), o trabalho familiar é simultaneamente necessário e repartido não só de forma desequilibrada, mas a priori. É o "não dito" do casamento, como da organização social, que mina o modelo de paridade entre cônjuges, enfraquecendo simultaneamente a posição da mulher, quer nas relações conjugais quer relativamente ao mercado de trabalho. Destaca também que o trabalho doméstico continua a ser atribuído à mulher mesmo quando esta trabalha, apesar do ligeiro aumento da participação dos pais no cuidado dos filhos.
}

impulsionadas pela crise e pelas reformas neoliberais, a sociedade civil - e, mais especificamente, a família - aparece com papel renovado na proteção social.

O setor privado (lucrativo, filantrópico e não governamental) e os setores informais (família e comunidade) retornam como fontes de proteção social, tomados como mais eficientes, eficazes e com reduzido custo. Entretanto, como o mercado volta-se cada vez mais para a satisfação de necessidades lucrativas (voltado, portanto, para os que detêm poder de compra), uma enorme sobrecarga recairá sobre a família, que funciona como "amortecedora" da crise, "absorvedora de choque", instrumento de redução do sentimento de exclusão social e de promoção de bem-estar de seus membros.

Bermúdez (2001) denomina esse processo de "neofamiliarismo", uma tendência ideológica de fazer da família uma unidade econômica e política de resolução de problemas da racionalidade global do sistema, ao lado de tentativas de "reprivatizar" atividades antes grandemente assumidas pelo poder público e pela sociedade em geral, como os riscos sociais de responsabilidade da coletividade.

Em síntese, pode-se dizer que a ascensão da família como referência da política social emerge num contexto de crise e de críticas ao Estado de Bem-Estar Social. Entre as críticas, destacam-se a impossibilidade financeira de que o Estado continue arcando com a provisão do bem-estar e o crescente individualismo e a acomodação promovidos pela garantia de acesso à proteção social pública. Dentre as propostas de saída da crise, destaca-se o pluralismo de bem-estar social.

Conforme Pereira (2006), o pluralismo de bem-estar social prevê a distribuição e a provisão do bem-estar social por um agregado de instâncias provedoras e gestoras nesse campo, composto por quatro setores: o setor oficial, identificado pelo Estado; o setor comercial, identificado pelo mercado; o setor não governamental, das instituições sem fins lucrativos da sociedade civil; e o setor informal, identificado com as redes primárias e informais de apoio desinteressado e espontâneo, (constituído por família, vizinhança e grupos de amigos). Isso significa uma divisão de responsabilidades, não apenas de financiamento - que responsabiliza 
a sociedade pela proteção de todos -, mas na execução da política, como parte da rede que deve prover a proteção social. Trata-se de uma nítida parceria entre público e privado ou do reforço da sociedade providência e da família cuidadora, integradora e geradora de vínculos.

Se, como salienta Esping-Andersen (1999), são incorretas para todos os países as ideias de que as funções da família foram deslocadas com o advento do Estado de Bem-Estar Social, e de que os Estados, com algumas exceções, investem grandemente em transferência de renda e apenas marginalmente dedicam-se a serviços para a família, em contexto de austeridade de gastos, crescimento de desemprego e busca de soluções privadas para as necessidades sociais não se caminha no sentido de aprofundar modelos mais igualitários e universalistas. Antes, são reforçadas as características históricas dos seus sistemas, em especial o familismo, que tende a aumentar em muitos países.

Em muitos Estados não há um "ressurgimento" da família, uma vez que essa sempre foi ativa $^{7}$ nas funções de reprodução social, mas sim um "reforço" das suas funções clássicas, ou a "sobrecarga" com novos papéis e deveres. Isso ocorre em um contexto de crise e desemprego, inclusive gerado pelas políticas públicas. Os governos, que, ao tomar como objeto de intervenção as famílias pobres, concebem-nas como espaço de proteção social, mas também como alvo dessa proteção, geralmente na perspectiva de otimizá-la, somando a proteção fornecida pela família à que é realizada pelas instituições públicas e minimizando, assim, custos com a institucionalização. É nesse contexto que a família é retomada na política pública.

\section{Considerações finais}

A relação família versus proteção social, analisada neste estudo, demonstra que o Estado cada vez mais intervém no campo da reprodução social, como já foi destacado por Saraceno (1992). Este também é o campo da

\footnotetext{
${ }^{7}$ Barros (1995, p. 119) diz que "consultas realizadas nos últimos anos pela UNESCO sobre o futuro da família em todas as regiões do mundo (Benham, 1990), descartam a ideia da decadência da família e confirmam que esta conserva em todas as partes seu vigor, se bem que se destaca a diversidade estrutural e funcional dos sistemas familiares".
}

família, o que não vem significando diminuição de responsabilidades, mas sim o seu reforço, pois o Estado atua tomando a família como um de seus interlocutores e "parceira" na proteção social. Encara a família como um dos sujeitos da rede social a ser potencializado e desenvolvido para utilizar suas estratégias e recursos internos.

Na sul da Europa, no Leste europeu, na América Latina, onde a família nunca deixou de ser uma unidade produtora e provedora de serviços, realizados, em grande parte, pelo trabalho não pago da mulher - entre eles o cuidado, as tarefas de socialização, educação e proteção o reforço dessas funções pela política dirigida à família no contexto de reformas das políticas sociais, de welfare mix, significa a permanência da reprodução social no âmbito privado. Significa também a reprodução da divisão sexual do trabalho, além de onerar ainda mais as mulheres e trazer severas consequências no desenvolvimento de sua cidadania social.

O "neofamiliarismo" ou "familismo" é uma tendência dos regimes de bem-estar na América Latina, e na orientação das novas políticas sociais. Essa perspectiva de responsabilização das famílias para além das suas possibilidades reforça a dependência dos serviços, recursos e apoios familiares por parte de seus membros.

A defesa de um projeto protetivo para as famílias e indivíduos requer uma política desfamiliarizante. Uma política que oferte serviços de suporte; que secundarize suas funções de reprodução social; que ofereça serviços universais, de acesso local, em quantidade e qualidade, sistemáticos e continuados; que garanta direitos e gere independência para jovens, idosos, muIheres; e que democratize as relações familiares, defendendo e oferecendo serviços que autonomizem os membros mais frágeis e dependentes na hierarquia familiar.

Fortalecer a vida familiar é dar-lhe possibilidades nesse contexto de vulnerabilidade que a desagrega; é não reforçar responsabilidades para otimizar as reduzidas ofertas de serviços públicos e privados (mercantil e não mercantil); é não reforçar as relações de dependência dos indivíduos dos recursos, serviços e cuidados familiares, mas, sim, fornecer uma sustentabilidade material e de serviços que ofereça proteção aos seus membros, cumprindo funções que a família, em decorrência de 
contingências sociais, econômicas, políticas e culturais, vem tendo dificuldade para exercer.

\section{Referências}

ADORNO, T. W.; HORKHEIMER, M. Sociologia da família. In: CANAVACCI, M. (Org.). Dialética da família: gênese, estrutura e dinâmica de uma instituição repressiva. São Paulo: Brasiliense, 1987.

BARROS, A. P. El analise de las políticas sociales desde una perspectiva familiar. Serviço Social e Sociedade, São Paulo, Cortez, n.49, ano XVI, p.117-32, nov.1995.

BERMÚDEZ, M. S. D. M. Políticas Sociales y familia: Estado de Bienestar y neoliberalismo familiarista. Revista Fronteras, Montevidéu, Universidad de la República, n.04, p.103-44, set. 2001.

CAMPOS, M. S. Família e proteção social: alcances e limites. In: ZOLA, M. B. (Org.). Cooperação internacional para proteção de crianças e adolescentes: o direito à convivência familiar e comunitária. São Bernardo do Campo - SP: Fundação Criança de São Bernardo do Campo, 2008a.

A metodologia e seus componentes. Metodologias do trabalho social. São PaulolBrasília: IEE-PUC-SPICAPES, 2008b.

; MIOTO, R. C. T.; LIMA, T. C. Quem cobre as insuficiências das políticas públicas? Contribuição ao debate sobre o papel da família na provisão de bemestar social. Revista de Políticas Públicas, São Luís, Universidade Federal do Maranhão, n.10, v.1, p.165-85, jan.ljun. 2006

CARVALHO, M. C. B. Família e políticas públicas. In: ACOSTA, A. R.; VITALE, M. A. F. (Orgs.). Família: redes, laços e políticas públicas. 3.ed. São Paulo: CortezIPUCSP-IEE, 2005.

CASTEL, R. As metamorfoses da questão social: uma crônica do salário. Petrópolis, RJ: Vozes, 1998.

DI GIOVANNI, G. Sistemas de proteção social: uma interpretação conceitual. In: OLIVEIRA, M. A. (Org.). Reforma do Estado e políticas de emprego no Brasil. Campinas, SP: UnicamplIE, 1998.

DRAIBE, S. M.; RIESCO, M. Estado de bienestar, desarrolo económico y ciudadanía: algunas lecciones de la literatura contemporánea. Cadernos n.77, Campinas-SP: UnicampINEPP, 2006.

ESPING-ANDERSEN, G. As três economias políticas do Welfare State. Lua Nova, São Paulo, n.24, p.85-116, set. 1991
Social Foundations of Posindustrial Economies. Nova York: Oxford, 1999.

FERRERA, M. A reconstrução do Estado Social na Europa Meridional. Análise Social, Lisboa, Instituto de Ciências Sociais da Universidade de Lisboa, p.457-75, 2000.

.; HEMERIJCK, A.; RHODES, M. O futuro da Europa social: repensar o trabalho e a proteção social na nova economia. Oeiras, Portugal: Celta Editora, 2000.

(Org.) Welfare State Reform in Southern Europe: fighting poverty and social exclusion in Italy, Spain, Portugal and Greece. Nova York: Routledge, 2005.

FRANZONI, J. M. Domesticar la incertidumbre en América Latina: Mercado laboral, política social y família. São José, Costa Rica: Editorial UCR, 2008.

HABERMAS, J. Mudança estrutural da esfera pública. Rio de Janeiro: Tempo Brasileiro, 1984.

HELLER, A. A concepção de família e Estado de BemEstar Social. Serviço Social e Sociedade, São Paulo, Cortez, Ano VIII, p.5-31, ago. 1987.

LAVINAS, L. Gênero, cidadania e políticas urbanas. In: RIBEIRO, L. C.; JÚNIOR, O. A. S. Globalização, fragmentação e reforma urbana: o futuro das cidades brasileiras na crise. São Paulo: Civilização Brasileira, 1994.

NAVARRO, V. Bienestar insuficiente, democracia incompleta: sobre lo que se habla en nuestro país. Barcelona: Editorial Anagrama, 2002.

PEREIRA, P. A. P. Mudanças estruturais, política social e papel da família: crítica ao pluralismo de bem-estar. In: SALES, M. A; MATOS, M. C.; LEAL, M. C. (Orgs.). Política Social, família e juventude: uma questão de direitos. São Paulo: Cortez, 2.ed. 2006.

SARACENO, C. Sociologia da família. Lisboa: Estampa, 1992.

SILVA, L. M. R. R. Serviço Social e família: a legitimação de uma ideologia. 3.ed. São Paulo: Cortez, 1987.

SUNKEL, G. El papel de la família en la proteccíon social en América Latina. Chile: Cepal, 2006 (Série Políticas Sociales, n.120).

VIANA, A. L. A.; LEVCOVITZ, E. Proteção social: introduzindo o debate. In: et al. (Org.). Proteção Social: dilemas e desafios. São Paulo, Hucitec, 2005. 